\title{
The Application of E-Commerce in Small and Medium-Sized Enterprise Purchasing Management
}

\author{
Yongxia Zhang \\ Hohhot Vocational College, Inner Mongolia \\ Hohhot, Inner Mongolia,china \\ Zhangyongxia456@aliyun.com
}

\begin{abstract}
The small and medium-sized enterprises play an irreplaceable role in building a harmonious society, promoting economic development, increasing employment opportunities, promoting independent innovation, optimizing the trade structure,But duing to its small scale, limited funds, general procurement cycle is not stable, procurement volume is small ,The small and medium-sized enterprise faced greater market volatility. In this article, The author analyzed the characteristics of small and medium-sized enterprises, and improved and optimized the procurement method to save the purchasing cost, promoted small and medium-sized enterprise management level and market competitiveness, promoted the small and medium-sized enterprises sustained, healthy and rapid developed .
\end{abstract}

Keywords- Small and medium-sized enterprises; electronic commerce; purchasing management

\section{INTRODUCTION}

As well as knows that the small and medium-sized enterprise is an important part of our national economy, they play a decisive role in promoting economic development and social stability. According to the national development and Reform Commission SME Department statistics, at the end of june, 2007 ,China's small and medium-sized enterprises has reached about 42000000 , accounting for $99.8 \%$ of total number of enterprises, creating about $60 \%$ of GDP. However, according to statistics, the average life of small and medium-sized enterprises only 2.9 years. According to the national development and Reform Commission 's statistics, the impact of the financial crisis, the first half of 2008, China has about 6.7 million of small and medium-sized enterprises closed down. Obviously, the survival of small and medium enterprises in the fierce market competition are very difficult, resisting market risk ability is weak. The reason is that our small and medium-sized enterprise development history is short, small size of output, less personnel, capital and technology constitute a relatively low, capital is relatively weak, non-standard business processes, not scientific, effective, lasting control can not be implemented; at present, in the global financial crisis is still spreading in the background, the internal management problems about small and medium-sized enterprises have become increasingly prominent, especially the procurement management .

\section{ELECTRONIC COMMERCE}

E-commerce, usually refers to the trading parties or participants using computer technology and network technology, mainly (the Internet) of modern information technology do all kinds of business activities, including trade in goods, trade in services and intellectual property trade, etc. As for it definition is no clear, UN working group on electronic commerce trade procedures simplified definition is: use electronic form to carry out business activities, including between suppliers, customers, government and other parties through any electronic tools, such as EDI and Web technology, E-mail sharing unstructured or structured business information, and manage and complete business activities, management and consumption activities in various trades. In currently ecommerce transactions can infiltrate the trading activities at various stages, including information exchange, before, after-sales service, electronic payments, transportation, forming a virtual enterprise, Shared resources, etc.its participants include manufacturers, vendors,Industrial and commercial enterprises, financial institutions, government agencies, enterprises and institutions and individuals. Ecommerce to break the regional restrictions, short the time of the flow of information and make more close to the production and consumption, reduce the processing cost, logistics, cash flow and information flow transmission. its features can be summarized as: transaction virtualization, low cost, efficient, trading transparency, scalability, and collaborative. Different types of e-commerce has given rise to different electronic trading market, combined with the classification of electronic commerce, electronic market can be divided into B2C, B2B, C2C, etc. Such as dangdang, joyo amazon, belongs to the model of B2C ebay, taobao, etc to belong to $\mathrm{C} 2 \mathrm{C}$. While such as alibaba, made in China web belong to $\mathrm{B} 2 \mathrm{~B}$ electronic market. As transactions between enterprises of electronic commerce mode, B2B electronic market transactions accounted for $80 \%$ of the world's total e-commerce transactions, it become the body of today's global e-commerce trade.B2B electronic market according to its different can be divided into enterprise platform and social platform. 


\section{THE PROCUREMENT PROBLEM OF SMALL AND MEDIUM-SIZED ENTERPRISES}

A. here are many small and medium-sized enterprise informationization consciousness is weak, management is backward, which not fully aware of the importance of the information age economy occupy the market, how to develop e-commerce understanding is not comprehensive enough, some believe that e-commerce is the Internet, some believe that e-commerce is a website, this understanding is one-sided, electronic Commerce Management related basic have not kept pace with the development of enterprises, only stay at a construction site. Therefore, many enterprises not only to take the electronic commerce in the thought, should be more substantial to the electronic commerce to understand. At the same time, the electronic commerce is not an enterprise or business to do, but a trend of globalization. If an enterprise supply chain management lacks the consummation, the core enterprise and supply chain cooperation is a problem.

B. a short-sighted enterprises often do not have great prospects for development, many small and mediumsized enterprises lack of foresight and long-term planning, to the immediate short-term benefits for weight. Electronic commerce involves many aspects, including business transformation and the development of electronic commerce mode. Using the network browsing, collected and published sources, has been to establish their own corporate website and information platform, and then to the implementation of online purchasing and industry combined platform, finally improve their supply chain management, implementation and development of small and mediumsized enterprises in e-commerce. Step can not be, be implemented step by step, and gradually put in place, if only the immediate interests, enterprises will never have to develop.

\section{ELECTRONIC PROCUREMENT MODE OF SMALL AND MEDIUM-SIZED ENTERPRISES.}

\section{A. The Seller Mode}

Seller model (Sell sideModel) is defined as a vendor to increase market share, develop their own Internet website, announced its products online catalog, allows for a great deal of the enterprise to obtain the required commodity information by browsing, to make the purchase decision, the buyer load the seller system Is usually free, the examples of this model are stores or shopping center. for the buy party, the advantage of this model is easy to access, easy to obtain the required product information, and does not require any investment, the disadvantage is difficult to track and control the procurement costs.the purchaser had to face internal electronic procurement information with the back-end enterprise integration problem cannot be well, because the procurement and suppliers are communicate by supplier system, the two sides using the standard may be different, information system supplier system to the electronic document purchasing transmission can not be purchase party recognited and processed automatically and transmitted to the relevant responsible office. these documents must go through manual processing, greatly reduced efficiency low electronic procurement, prolong the procurement .In addition, the purchaser must to select, find and browse suppliers through large supplier web sites, and every time input the relevant required:company name address,telephon number.Account, and then update the ERP system.it have hundreds of supplier companies through this model to the procurement the required items really is a time-consuming and laborious .

In recent years, XML (extensible Make up Language) technology, and provides a new idea and transmission on the Internet data representation,it has become the preferred solution technical specification for definition of data exchange format between Intemet e-commerce applications in a variety of XML technologies built have been introduced, mainly XMLarchitecture.RNIF,UDDI,XML/EDI and being developed by the China electronic commerce standard C watts XML.these standards of Intenet are become the main communication facilities, being XML as the description language, business data semantic business process bill format,Message service as the core, mainly to solve the data sharing service business partners! The security problem, collaborative! Make B2B Electronic Procurement Based on Internet has a new development

\section{B. The Buyer Mode}

Buyer model (Buy side Model) refers to the purchaser release of required procurement of products on the Internet, suppliers to log in to get your product information in the purchaser's website, for the procurement party assessment, and communication of information further by Purchaser site,ffrom both sides, they must completed a total of purchasing business in this mode, the purchaser to establish, maintain and update product catalog work,although this costly, but the purchaser of the purchasing process can control it, limit the types and specifications of products required in the directory,,even can give different employees in purchasing different products set procurement authority and quantitative restrictions".in addition,the staff only need to understand that all possible suppliers information through an interface can.and convenient for comparison and analysis "at the same time, because the supply and demand sides is document delivery by purchasing the site, therefore the purchase site between the purchaser information system seamless connection to these documents are the background of system identification .

But in this one mode, due to the large number of suppliers in the directory list maintenance and management system, the seller need funding and system maintenance cost, and between children business negotiation and cooperation, this is because the buyer has actually responsible for the maintenance of the current product availability, delivery cycle and price! Description. For a successful buyer mode, using the mature information 
technology to ensure its safe operation is extremely important. Enterprises should establish a technology perfect security system: security defense system is arranged in the internal, limiting Cheng Denglu far, Intemet hacker attack means to understand promptly, to the operation of the system administrator permissions dual protection, timely data backup; take IP firewall Tsuen on router in the hitemet interface! Application layer firewall and virus firewall technology based on host, to prevent external viruses and hackers: at the same time, business data interaction between the encrypted digital signature identification technology!! "only adopts the technology of protection means to in order to ensure that the procurement processs moothly.

\section{The Market Model}

Market model is a process of supplier and purchaser through third party website set up by the procurement business. In this mode, both supplier and purchaser are only released in third party website and describe themselves or in need of product information.the third party website is responsible for product information and convenient for users to use. Although this model omits the procurement party website to spend, but the market is the third party website independently, it is integrated with the background system

procurement is also difficult to remedy this defect, the number of online trading market especially electronic procurement scheme provides emarket, which have adopted the XML architecture based on open type, this architecture has gradually become the mainstream mode of construction of emarket because in this framework, regardless of the system of enterprise language, can be through the XML smoothly / communication. At the same time, they also provide for the customer service integration background, so that enterprises smoothly through The procurement of electronic market.

The small and medium-sized enterprise general direct material purchasing,because of the small and medium-sized enterprises do not have a complete enterprise information system.The system integration is high is not a key factor to determine the direct material purchasing mode, at this time, between the purchaser and supplier strength and relationship becomes the key problem of" determine if the supplier is a large enterprises, purchase the purchaser is only a small part of the supplier sales, the buyer usually best to use the pattern: if the supplier is also small and medium enterprises, can be through the third party market mode in "the small and medium-sized enterprise MRO purchasing for many small and medium-sized enterprises, the third market model is the only way in MRO material purchase ideal.

\section{THE EFFECTION OF USING ELECTRONIC PROCUREMENT}

A. It can expand the range of suppliers, improve the purchasing efficiency, reduce the cost of procurement, production scale as e-commerce procurement facing the market from local to national and even global market, it can break through the traditional procurement model limitations, find satisfactory suppliers based on quality and price of, greatly reduce the purchasing cost .because they do not need to travel, can greatly reduce the purchasing cost, through sharing information website, it can save paper, to achieve paperless office, greatly improve the efficiency of procurement"

$B$. Improve the transparency of procurement,Since the initial e-commerce procurement in both sides of the transaction does not meet, the purchasing information at specific sites, the procurement process open, avoid personal contact both parties concerned, conducive to the realization of real-time monitoring, to avoid the purchase of a black hole, to purchase more for transparent.

$C$. Conduce to the realization of the procurement business process standardization,Electronic commerce is based on Optimization of the business process, must be carried out according to standard process of software requirements, can standardize the purchasing behavior, standardize procurement market to establish a good economic and social environment, greatly reducing the procurement process at"

D. Meet the just-in-time and flexible manufacture mode, shorten the procurement cycle.

\section{REFERENCES}

[1] Barefield, R.M. The Impact of Audit Frequency on the Quality of Internal Control.American Accounting Associa-tion, 1975.

[2] Bodnar,G.. Reliability Modeling of internal contol [M]. The Accounting Review, 1975.

[3] Lili Sun, Rajendra P. Srivastava, Theodore J. Mock. An Information SystemsSecurity Risk Assessment Model Under the Dempster-Shafer Theory of BeliefFunctions, Journal of Management Information Systems, v.22 n.4, 2006, 109-142,Number 4/Spring .

[4] Philips C, Meeker M. The B2B Internet Report: Collaborative Commerce[R]. Morgan Stanley Dean Witter Equity Research, April 2000.

[5] Kaplan S, Sawhney M .E-hubs. The new B2B marketplaces [J]. Harvard Business Review,2000, 78(3):97 - 103. 